\title{
Limited possibilities for prezygotic barriers in the reproductive behaviour of sympatric Ophthalmotilapia species (Teleostei, Cichlidae)
}

\author{
Loïc Kéver ${ }^{\mathrm{a}, \mathrm{b}, *}$, Eric Parmentier ${ }^{\mathrm{b}}$, Sofie Derycke ${ }^{\mathrm{c}, \mathrm{d}}$, Erik Verheyen ${ }^{\mathrm{c}}$, Jos Snoeks ${ }^{\mathrm{e}, \mathrm{f}}$, \\ Maarten Van Steenberge ${ }^{\mathrm{c}, \mathrm{e}, \mathrm{f}}$, Pascal Poncin ${ }^{\mathrm{a}}$ \\ ${ }^{a}$ Laboratory of Fish and Amphibian Ethology, Behavioural Biology Unit, Liège University, 4000 Liège, Belgium \\ ${ }^{\mathrm{b}}$ Laboratory of Functional and Evolutionary Morphology, Liège University, 4000 Liège, Belgium \\ c Operational Directorate Taxonomy and phylogeny, Royal Belgian Institute of Natural Sciences, 1000 Brussels, Belgium \\ d Department of Biology, Ghent University, 9000 Ghent, Belgium \\ e Section Vertebrates, Ichthyology, Royal Museum for Central Africa, 3080 Tervuren, Belgium \\ ${ }^{\mathrm{f}}$ Laboratory of Biodiversity and Evolutionary Genomics, University of Leuven, 3000 Leuven, Belgium
}

\section{A R T I C L E I N F O}

\section{Keywords:}

Cichlidae

Hybridisation

Ophthalmotilapia

Reproductive Behaviour

Sound

\begin{abstract}
A B S T R A C T
Since prezygotic rather than postzygotic barriers are believed to maintain the diversity of closely related sympatric cichlids, differences in phenotypic traits and reproductive behaviours are likely involved in maintaining species boundaries. Here, we focused on the reproductive behaviour of three Ophthalmotilapia species with distributions that only overlap on a small stretch of the shore line of Lake Tanganyika. Repeated introgression of mitochondrial DNA between these species was previously reported, which suggested they can hybridise. Our aim is to test the hypothesis that reproductive behaviour acts as a prezygotic barrier that prevents frequent hybridisation in sympatric Ophthalmotilapia species. We performed a quantitative analysis of twelve reproductions (four for $O$. ventralis, six for $O$. nasuta, one for $O$. boops, and one between a female $O$. ventralis and a male $O$. nasuta). Although similar ethograms were obtained for these reproductions, the $O$. ventralis and $O$. boops males displayed a behaviour that was never performed by $O$. nasuta males. This behaviour was displayed during courtship and we called it 'invite'. In O. ventralis, we could show that it was associated with the emission of a single pulse sound. The comparison of $O$. nasuta and $O$. ventralis reproductive behaviours also revealed some quantitative differences: $O$. ventralis males showed the location of the bower more often to the female, whereas $O$. ventralis females followed the male more often. The similarity between the reproductive behaviours in $O$. ventralis and $O$. nasuta could explain the occurrence of the heterospecific spawning event recorded between an $O$. nasuta male and an $O$. ventralis female. Importantly, few eggs were laid and the maternal mouthbrooding that resulted from this heterospecific reproduction only lasted for two days, which suggested the abortion of egg development. Hence, in the absence of conspecifics, courtship and mating behaviours alone do not constitute perfect prezygotic barriers between these two species.
\end{abstract}

\section{Introduction}

Cichlid species flocks from the East African Great Lakes are classic examples of adaptive radiation (Day et al., 2008). With ca. 210 cichlid species grouped in 15 tribes, the cichlid assemblage of Lake Tanganyika (LT) is the least speciose of the three largest East African Lakes (Day et al., 2008). Yet, it is the oldest and the most diverse in terms of phylogeny (Salzburger et al., 2002a; Koblmüller et al., 2008), brood care, reproductive tactics, mate traits, and mating behaviour (Kuwamura, 1986; Sefc, 2011; Morita et al., 2014). For example, while the endemic cichlids from lakes Malawi and Victoria are all maternal mouthbrooders, LT cichlids show at least five types of parental care (Taborsky and Limberger, 1981; Kuwamura, 1986): biparental or maternal incubation in mouthbrooders, and maternal, biparental, or cooperative (i.e. parents and helpers) guarding in substrate brooders. Since prezygotic rather than postzygotic barriers are believed to maintain the diversity of closely related sympatric cichlids (Kornfield and Smith, 2000), differences in phenotypic traits and reproductive behaviours are likely involved in maintaining species boundaries. Yet, many instances of hybridisation have been found in Great Lake cichlids (Rüber et al., 2001; Salzburger et al., 2002b; Smith et al., 2003; Egger et al., 2007; Koblmüller et al., 2007; Keller et al., 2013), which may

\footnotetext{
* Corresponding author at: Laboratory of Functional and Evolutionary Morphology, Liège University, 4000 Liège, Belgium.

E-mail address: loic.kever@ulg.ac.be (L. Kéver).
} 
have played an important role in shaping the cichlid radiations (Seehausen, 2004; Sefc et al., 2017). Female mate choice, potentially based on male reproductive behaviour, has been suggested as the main barrier for hybridisation in cichlids (Kocher, 2004). So far, emphasis has been placed on the role of colour patterns (Kocher, 2004; Seehausen et al., 2008; Egger et al., 2010) and McElroy and Kornfield (1990) failed in the attempt to identify barriers to hybridisation in the reproductive behaviour of the mbuna species flock of Lake Malawi. However, they recognised that some differences may not have been quantified in their analysis and differences in the frequency with which courtship behaviours are performed were considered as sufficient to explain the reproductive isolation of two cichlids from Central America (Baylis, 1976). Additional efforts are needed to assess the role of reproductive behaviour in the evolutionary history of African cichlids (McElroy and Kornfield, 1990).

Here, we present a study on the genus Ophthalmotilapia, a member of the tribe Ectodini, containing four valid species (Hanssens et al., 1999): Ophthalmotilapia ventralis, O. boops, O. nasuta, and O. heterodonta. The status of the latter two species, which occur in allopatry, is still debated as the morphological differences between them fail to designate some populations to either of the two species (Hanssens et al., 1999; Nevado et al., 2011; Konings, 2014). Ophthalmotilapia can be distinguished from all other ectodine genera by the bifid spatulae at the distal end of the male pelvic fins (Liem, 1981; Hanssens et al., 1999). Because of their similarity in colour and shape to eggs, these spatulae are suggested to function as egg dummies during reproductive behaviour (Haesler et al., 2009; Immler and Taborsky, 2009).

Although Ophthalmotilapia has a circumlacustrine distribution, the distributions of the four species differ strongly (see Hanssens et al., 1999 for distribution maps). This could be a consequence of their different habitat preferences. Ophthalmotilapia nasuta prefers so-called intermediate habitats (i.e. sand with rocky patches) and can be found throughout the lake (Konings, 2014). The other three species have more restricted distributions and only occur at rocky shores (Konings, 2014). Ophthalmotilapia ventralis and $O$. heterodonta have non-overlapping distributions, with the former species occurring in the southern third and the latter in the northern and central parts of the lake. Ophthalmotilapia boops is only present along a small part of the south-eastern lake shore. This part of the lake forms the only stretch where three Ophthalmotilapia species occur in sympatry (Hanssens et al., 1999; Nevado et al., 2011). In this region, a comparison of mitochondrial markers and microsatellite patterns revealed hybridisation events mostly between $O$. nasuta males and females of $O$. ventralis and $O$. boops (Nevado et al., 2011)

All Ophthalmotilapia species are sexually dimorphic. Males attain a larger size than females and their bodies are generally deeper. Unlike females, mature males have prolonged pelvic fins, almost reaching to the origin of the caudal fin and terminating in bifid spatulae (Hanssens et al., 1999). They also show a spectacular colour pattern, while females are generally paler and uniformly coloured (Schupke, 1994). Territorial males manage a breeding site or bower that differs in size and shape depending on the species (Kuwamura, 1986; Morita et al., 2014); some build sand craters while others clean a small area on a rock, for example. The reproductive behaviour of $O$. ventralis has been briefly described by Haesler et al. (2009) and Immler and Taborsky (2009) as follows: (1) a territorial male approaches a female; (2) after a quick lateral display, the male swims to his bower with an exaggerated undulation of the tail; (3) the female follows the male and enters the bower; (4) the male places his genital papilla onto the bower and quivers (probably releasing sperm); (5) he subsequently presents the egg dummies where he has just quivered; (6) the female may take the egg dummies into her mouth; (7) the male leaves the bower and defends the territory; (8) the female lays an egg (up to three eggs in successive turns), takes it up in her mouth quickly and leaves the bower. According to Kuwamura (1986), females always lay one egg at a time. After the female leaves the bower, the male starts to court the female again and the pair can start another spawning bout (Immler and Taborsky, 2009). Some parts of the reproductive behaviour of $O$. nasuta and $O$. boops have also been mentioned in the literature (Brichard, 1989; Loose, 2007; Konings, 2014; Morita et al., 2014). In spite of small contradictions in the descriptions given by these authors (e.g. absence or presence of pelvic fin presentation), they generally considered the reproductive behaviour of Ophthalmotilapia species to be similar. The sole interspecific difference that was clearly identified was the type of the bower. The male $O$. nasuta builds a large 'crater shape' sand mount while males from the other species dig a small bower in the sand or clean a flat rock. To date, no quantitative comparison of the reproductive behaviour based on data collected in controlled conditions has been provided.

Although repeated unidirectional introgression of nuclear and mitochondrial DNA from congeners into O. nasuta occurred (Nevado et al., 2011), hybrid phenotypes are rare in the lake and species boundaries are maintained even where they are living in sympatry. Therefore, we aimed to test the hypothesis that reproductive behaviour acts as a prezygotic barrier that prevents frequent hybridisation in sympatric Ophthalmotilapia species. To this end, we compared the reproductive behaviour of $O$. ventralis and $O$. nasuta using successful reproductive events recorded under controlled conditions. Our prediction is that interspecific differences in reproductive behaviour or in the timing of these behaviours could cause the female not to follow, lay eggs in the bower, or take the sperm of a heterospecific male. In addition, sound recordings were performed to identify potential differences in acoustic cues used by these two species. Two additional reproductions were recorded and analysed, one of $O$. boops and one of a heterospecific combination of a female $O$. ventralis and a male $O$. nasuta. These data were qualitatively compared with those obtained for $O$. nasuta and $O$. ventralis as they are of great interest when discussing the importance of prezygotic barriers in Ophthalmotilapia.

\section{Materials and methods}

\subsection{Fish collection and maintenance}

We purchased wild-caught individuals of Ophthalmotilapia from two commercial suppliers: 'Cichlidenstadl' (Alerheim, Germany) and 'Les Aquariums de Marbais' (Marbais, Belgium). We bought four O. ventralis coming from 'south of Moba' (DR Congo), and five $O$. ventralis, thirteen $O$. nasuta, and four $O$. boops from the surroundings of Ulwile Island (Tanzania).

We kept the fishes in monospecific tanks (photoperiod: 12:12 h L:D; water temperature: $26 \pm 1{ }^{\circ} \mathrm{C}$; carbonate hardness: $>8 \mathrm{dKH}$ ) at the University of Liège (Belgium) and fed them once a day with 'Tropical Spirulina forte' mini-granules ad libitum. Three males and four or five females, all adults, were introduced simultaneously in monospecific tanks with a single water circulation system and a similar layer of sand from the Loire river on the bottom. Hiding places and flat rocks were also provided. This setup worked well only for $O$. nasuta. In the tanks of $O$. ventralis and $O$. boops, courting behaviours were also observed within weeks but the constant aggressiveness of the males towards the females seemed to prevent the latter from mating. Hence, the setup for $O$. ventralis and $O$. boops was changed to monospecific tanks with a single male and three to four females per tank and individual filtration systems. Again, hiding places and flat rocks were provided. Although it took several weeks before a first reproduction was observed, this setup gave better results. Later, this setup was also tested on $O$. nasuta to check if the number of males in the tank had a strong impact on their reproductive behaviour. After the conspecific reproductions were recorded, three females of $O$. ventralis were kept with one male of $O$. nasuta. The other fish were kept in conspecific setups for other studies. All experimental procedures were approved by the University of Liège Institutional Animal Care and Use Committee (protocol \#1759). 
Table 1

Overview of data for the Ophthalmotilapia reproductions recorded.

\begin{tabular}{llllll}
\hline Species & Reproduction(s) & $\begin{array}{l}\text { Male } \\
\text { (s) }\end{array}$ & Females & Hydrophone & Tank(s) \\
\hline $\begin{array}{c}\text { Ophthalmotilapia } \\
\text { ventralis (OV) }\end{array}$ & 4 & 1 & 3 & 3 & $2 \times 260$ \\
$\begin{array}{c}\text { Ophthalmotilapia } \\
\text { nasuta (ON 1) }\end{array}$ & 3 & 1 & 4 & 1 & $1 \times 540$ \\
$\begin{array}{c}\text { Ophthalmotilapia } \\
\text { nasuta (ON 3) }\end{array}$ & 3 & $3^{*}$ & 4 to 5 & 3 & $1 \times 810$ \\
$\begin{array}{c}\text { Ophthalmotilapia } \\
\text { boops (OB) }\end{array}$ & 1 & 1 & 3 & 0 & $1 \times 800$ \\
$\begin{array}{c}\text { O. nasuta and O. } \\
\text { ventralis } \\
\text { (ONOV) }\end{array}$ & 1 & 1 (O. & 3 (O. nas) & 1 & $1 \times 260$ \\
vent) & & & &
\end{tabular}

Reproduction(s): number of reproduction(s) fully recorded; Male(s): number of male(s) in the tank; Females: number of females in the tank; Hydrophone: number of reproduction (s) also recorded by a hydrophone. Tank(s): number of tanks $\times$ volume (1). O. nas: Ophthalmotilapia nasuta; O. vent: Ophthalmotilapia ventralis; * two dominant and one subordinate males.

\subsection{Video recordings and analyses of the reproductive behaviour}

Every reproduction consisted of multiple spawning bouts, which means that most of the behaviours (e.g. female follows the male to the bower) were recorded multiple times during each reproduction: four reproductions for $O$. ventralis (OV), six reproductions for $O$. nasuta [three with one male and four females (ON 1) and three with three males (two dominants and one subordinate) and four to five females (ON 3)], one reproduction for $O$. boops (OB), and one heterospecific reproduction between an $O$. ventralis female from 'Moba' and an $O$. nasuta male (ONOV). We analysed every reproduction from $20 \mathrm{~min}$ before the first egg was laid to $10 \mathrm{~min}$ after the last egg was laid (Table 1). We never recorded the same mating female twice but it did happen that the same male was recorded more than once (three ON males for the six ON reproductions and two OV males for the four OV reproductions).

We defined nineteen behaviours (Table 2) using the nomenclature and descriptions by Baerends and Baerends-Van Roon (1950a). We encoded these behaviours as point (i.e. expansion in time is not recorded because it is very short) or state (i.e. expansion in time is recorded) events in the Boris v 2.72 open source software (Friard and Gamba, 2016). We encoded every behaviour from $20 \mathrm{~min}$ before the first egg was laid to $10 \mathrm{~min}$ after the last egg was laid. Moreover, when it was feasible, we tracked inviting behaviours and pelvic fin presentations up to one hour before the first egg was laid (e.g. not feasible when mating started early in the morning shortly after the light was turned on). This protocol allowed the production of ethograms (Fig. 1) and quantitative analyses in STATISTICA 12 (Statsoft, Tulsa, U.S.A).

\subsection{Sound recordings and analyses}

We placed a hydrophone [HTI Min-96, $-164.4 \mathrm{~dB}$ re. $1 \mathrm{~V} \mu \mathrm{Pa}-1$; bandwidth $2 \mathrm{~Hz}$ and $30 \mathrm{kHz}$ (Long Beach, MS, USA), or a Brüel and Kjær 8101 hydrophone connected to a calibrated Brüel and Kjær 2610 amplifier, sensitivity $-184 \mathrm{~dB}$ re. $1 \mathrm{~V} \mu \mathrm{Pa}-1$; bandwidth $0.1 \mathrm{~Hz}$ to $200 \mathrm{kHz}$ (Nærum, Denmark)] at half the height of the water column, over or just next to the bower. We connected this hydrophone to a Tascam DR-05 recorder (TEAC, Wiesbaden, Germany) at a sampling rate of $44.1 \mathrm{kHz}$. Sound recording devices were not always turned on because of the necessity to turn the aeration and the pumps off. Therefore, sounds were not recorded during some reproductions (Table 1). We processed and analysed the signal in Adobe Audition 2.0 (Adobe Systems Incorporated, San Jose, CA, USA). To prevent signal distortion by resonant frequencies, the signal was down-sampled at $10,000 \mathrm{~Hz}$ and low-pass filtered at $2,500 \mathrm{~Hz}$ (see Akamatsu et al., 2002). We also high-pass filtered the signal at $60 \mathrm{~Hz}$ to reduce the impact of low frequency noise (e.g. building vibrations and electrical noise). Lastly, we estimated the pulse duration (ms) and, in some cases, pulse period (ms) from the waveform, and the peak frequencies from power spectra.

Since the sounds emitted by Ophthalmotilapia individuals were very weak (i.e. low signal to noise ratio), we could only analyse the sounds emitted close to the hydrophone (source at max. two body lengths from the hydrophone). However, it seems likely that sounds linked to every type of behaviour would have been detected because each of them was performed several times in the vicinity of the hydrophone.

\subsection{Statistical analysis}

We first performed principal component analyses (PCAs) to have an overview of the possible interspecific differences in the reproductive behaviour. For these PCAs, we considered every reproduction event (four OV, three ON 1, three ON 3, one OB, and one ONOV) as an individual and the prevailing behaviours (i.e. behaviours that were consistently observed for at least one species) as the variables. For state variables, data types were percentages of the total time and scores (i.e.

Table 2

Behaviours used for the quantitative analysis of Ophthalmotilapia reproductions.

\begin{tabular}{|c|c|c|}
\hline & Nomenclature & Description \\
\hline $\mathrm{PE}$ & Bite & Fish bites another fish \\
\hline $\mathrm{PE}$ & Chase & Fish swims very fast towards another fish \\
\hline SE & Clean & Fish removes dirt/sand to clean/build the pit \\
\hline $\mathrm{PE}$ & Follow & Fish swims behind another fish \\
\hline PE & Frontal display & Fish spreads its pectorals, swells its throat, head high \\
\hline SE & Inside & Fish is inside the nest (less than one body length from the pit floor) \\
\hline $\mathrm{PE}$ & Invite & Fish performs a fast and unilateral contraction of its body musculature, generally head down, close to another fish \\
\hline $\mathrm{PE}$ & Lateral display & Fish presents his flank, swells its throat and leans slightly \\
\hline $\mathrm{PE}$ & Lay & Fish lies an egg \\
\hline $\mathrm{PE}$ & Lead & Fish swims at the front of another fish and guides it to the nest \\
\hline SE & Pelvics flickering & Fish alternatively moves its pelvic fins up and down (fast movements) \\
\hline $\mathrm{PE}$ & Present & Fish presents his pelvic fins to the mouth of a second fish, generally egg dummies are on the pit floor \\
\hline PE & Present over the back & Fish abducts the pelvics slightly swimming just over the female. The latter being inside the nest \\
\hline $\mathrm{PE}$ & Show & Fish stops at the entrance of the nest and tail waggle. \\
\hline $\mathrm{PE}$ & Sound & Fish emits an acoustic signal of interest \\
\hline SE & $\begin{array}{l}\text { Tail wagging/ } \\
\text { swimming on the spot }\end{array}$ & $\begin{array}{l}\text { Fish shakes the caudal part of its body (caudal fin and caudal part of the dorsal fin) with head slightly up or down }+ \text { Fish performs alternate forward } \\
\text { movements of the pectoral. }\end{array}$ \\
\hline $\mathrm{PE}$ & Take & Fish takes or tries to take something in mouth (modifiers: eggs or egg dummies) \\
\hline $\mathrm{PE}$ & Uncommon & Any uncommon behaviour that was recorded in rare occasions \\
\hline
\end{tabular}

PE: point event; SE: state event. 
A)

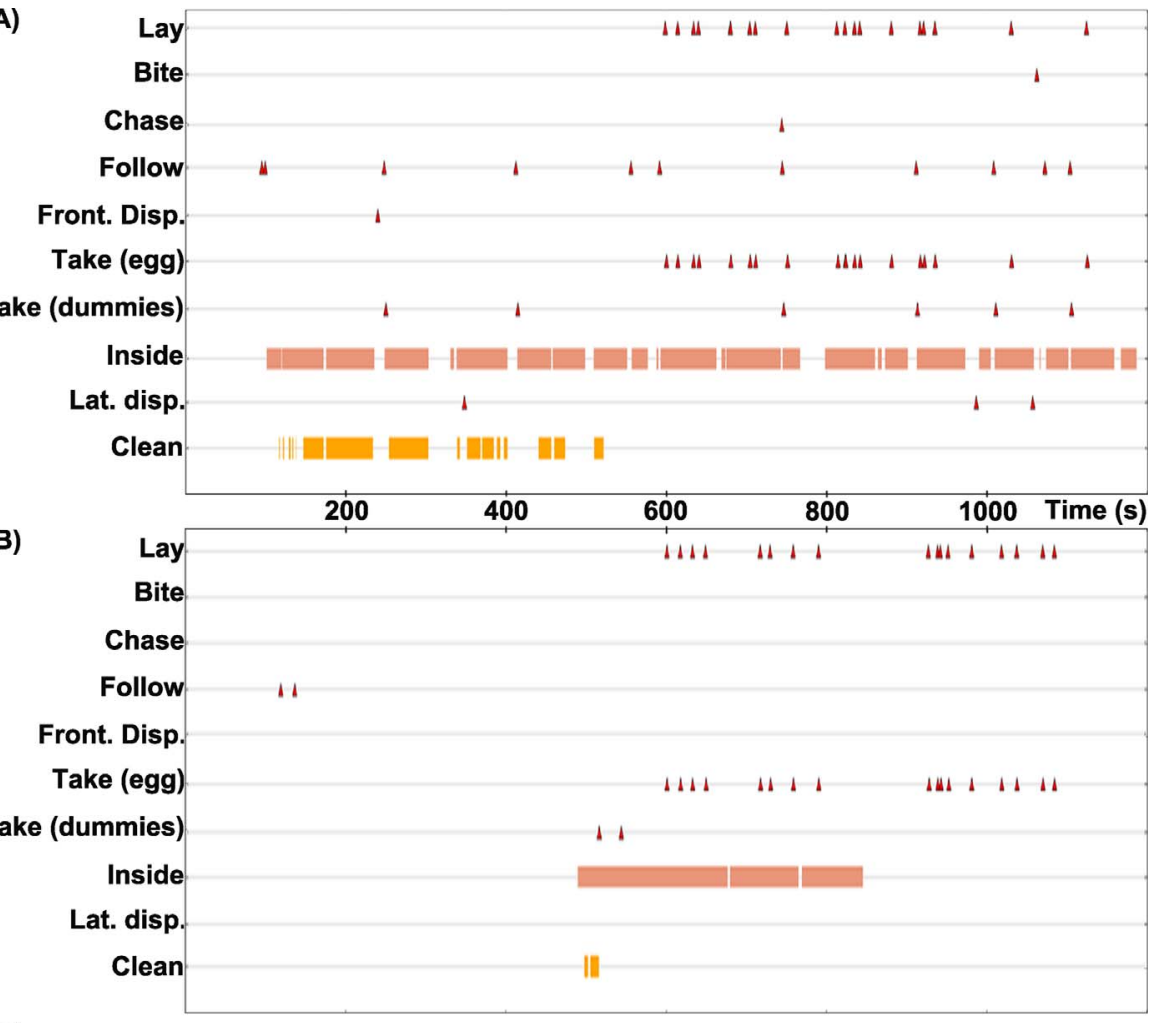

C)

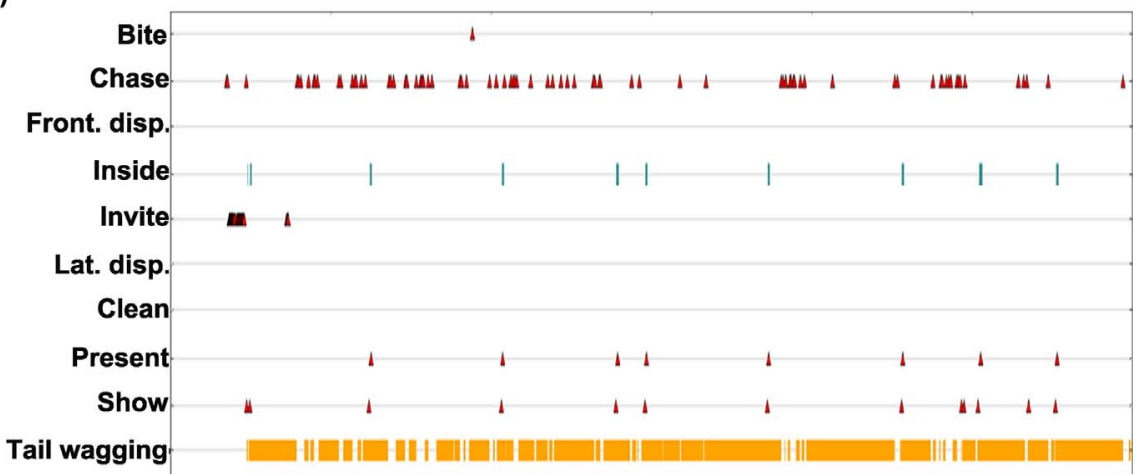

D)

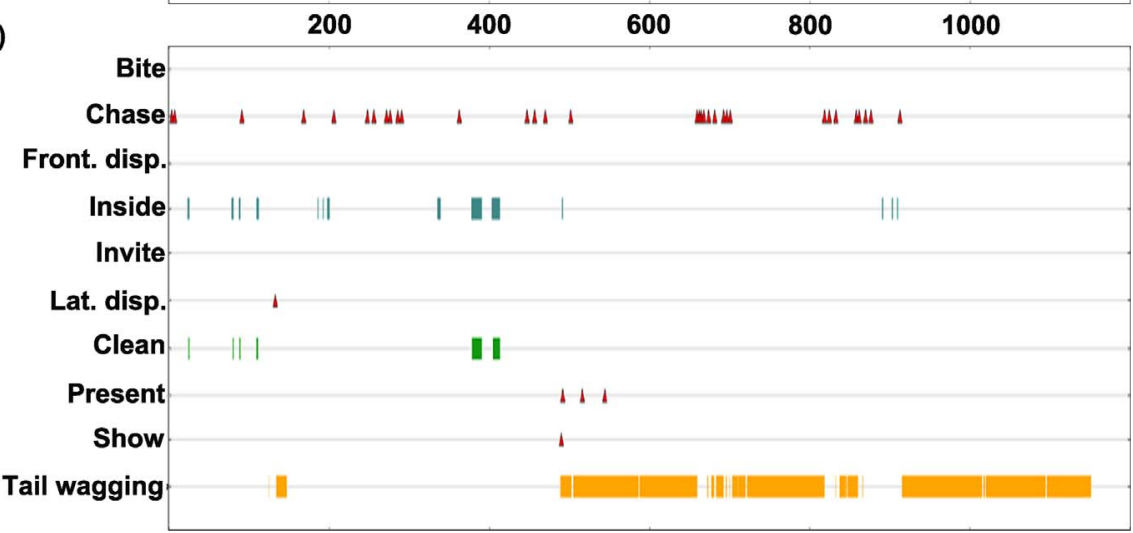

Fig. 1. Ethograms of Ophthalmotilapia ventralis and O. nasuta spawning bouts. Behaviour recorded from $10 \mathrm{~min}$ before to 10 min after the first egg was laid. A mating female $O$. ven tralis (A) and $O$. nasuta (B), and a mating male $O$. ventralis (C) and $O$. nasuta (D) were selected to illustrate the first spawning bouts of the reproduction in this genus. number of times a behaviour occurred), whereas for point variables, these were only scores. Data for males and females were analysed separately.

After data were tested for normality (Kolmogorov-Smirnov test for normality), we performed multi- ( $\mathrm{T}^{2}$ Hotelling) and uni-variate (Student $\mathrm{t}$ or Mann-Whitney $\mathrm{U}$ ) tests on the variables listed in Tables 3 and 4 to compare the reproductive behaviour of ON 1 and OV 1 . We excluded behaviours that were completely absent in one species (no 'invite', 'frontal display' and 'bite' recorded for ON 1). Results from univariate tests were adjusted using the sequential Bonferroni correction (Rice, 1989). For state variables like 'inside' and 'tail wagging', the Boris software provided scores and total duration. Here, we showed the percentage of the total time of the analysis for the variables 'inside' and 'tail wagging'. However, the results were similar when we used scores 
Table 3

Prevailing behaviours listed for the Ophthalmotilapia mating males.

\begin{tabular}{|c|c|c|c|c|c|}
\hline & OV $1(N=4)$ Mean $\pm S D$ & ON $1(\mathrm{~N}=3)$ Mean $\pm \mathrm{SD}$ & ON $3(N=3)$ Mean \pm SD & OB $1(\mathrm{~N}=1)$ & ONOV $(\mathrm{N}=1)$ \\
\hline Bite (n) & $3.8 \pm 4.8$ & $0 \pm 0$ & $7.3 \pm 8.6$ & 0 & 2 \\
\hline Chase (n) & $164.8 \pm 100.7$ & $52.3 \pm 28.4$ & $90 \pm 74.5$ & 63 & 233 \\
\hline Clean (n) & $12.5 \pm 10.5$ & $21.7 \pm 15.2$ & $11.3 \pm 14.5$ & 37 & 0 \\
\hline Frontal display (n) & $0.3 \pm 0.5$ & $0 \pm 0$ & $0 \pm 0$ & 0 & 0 \\
\hline Inside (n) & $51.8 \pm 41.2$ & $32 \pm 19.1$ & $54.7 \pm 59.2$ & 45 & 1 \\
\hline Inside (\%) & $4.5 \pm 2.4$ & $6.7 \pm 1.7$ & $6.1 \pm 3.8$ & 10.6 & $<0.1$ \\
\hline Invite (n) & $40.3 \pm 28.8$ & $0 \pm 0$ & $0 \pm 0$ & 20 & 0 \\
\hline Lateral display (n) & $0.3 \pm 0.5$ & $1.3 \pm 0.6$ & $0.7 \pm 1.2$ & 4 & 6 \\
\hline Present (n) & $12.5 \pm 3.9$ & $5.3 \pm 4.7$ & $19.3 \pm 10$ & 8 & 22 \\
\hline Show (n) & $17.3 \pm 1.3$ & $1.3 \pm 1.5$ & $20.7 \pm 8.3$ & 20 & 2 \\
\hline Tail wagging (n) & $76.3 \pm 45.1$ & $54.3 \pm 26.6$ & $119.3 \pm 59.1$ & 27 & 178 \\
\hline Tail wagging (\%) & $38.6 \pm 25.4$ & $42.5 \pm 24.6$ & $61.2 \pm 22.9$ & 46.7 & 36.3 \\
\hline
\end{tabular}

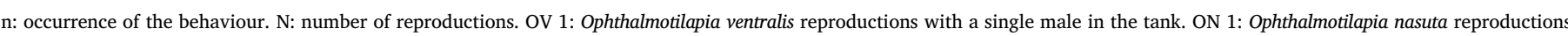

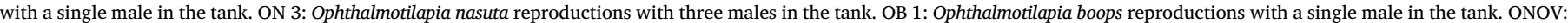

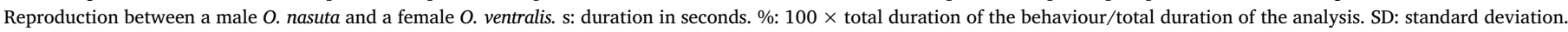

instead.

\section{Results}

\subsection{Ethogram of the reproduction behaviour in the genus Ophthalmotilapia}

We analysed twelve reproductions (four for $O$. ventralis, six for $O$. nasuta, one for $O$. boops, and one between a female $O$. ventralis and a male $O$. nasuta). The mean time recorded between the laying of the first and the last egg was approximately $25 \mathrm{~min}$ (mean $\pm \mathrm{SD}$ : $24.7 \pm 16.4 \mathrm{~min}$ ). Therefore, the mean time analysed was $55 \mathrm{~min}$ (see Section 2.2).

The reproductive behaviour in Ophthalmotilapia (O. ventralis, O. nasuta, and $O$. boops) is composed of several units called spawning bouts. These bouts are stereotypic and can be summarized in eight major steps (Fig. 2):

1) Male chases (a) and cleans (b): the territorial male digs or builds a bower, cleans its bower, and chases (i.e. swims very fast towards another fish) all male and female intruders off its territory.

2) Female follows: the mating female follows a male (generally after being chased) swimming back to its territory. At that time, the male starts to wag its tail (tail wagging). In $O$. ventralis and $O$. boops, a step called 'invite' (Fig. 3) often preceded step 2 during the first spawning bout of a reproduction. A male that 'invites' performs a fast and unilateral contraction of its body musculature, generally head down, close to a female (Fig. 3). This behaviour was generally repeated several times and associated with the emission of a short sound (at least in $O$. ventralis). Interestingly, we never observed the 'invite' in $O$. nasuta during our experiments.

3) Male shows the bower: the male swims to its bower and stops at the entrance until the female arrives. Throughout this step, the male always wags its tail, with its head slightly up.

4) Male presents pelvic fins: the male enters the bower, spreads its pelvic fins (perpendicular to the body), and places its bifid spatulae near the floor of the bower, using them as egg dummies.

5) Female tries to take egg dummies: female enters the bower (inside: start), swims towards the egg dummies, and opens her mouth.

6) Female lays $\operatorname{egg}(\mathrm{s})$ : the female lays an egg (sometimes 2 or 3 eggs one after another) in the bower. Male is tail wagging and chasing interacting fish of both sexes.

7) Female takes egg(s): the female takes the egg(s) in her mouth. Male is tail wagging and chasing interacting fish. Female generally repeats (6) and (7) several times before she proceeds to the next step.

8) Female leaves (inside: stop): female leaves the bower with eggs and/or sperm in her buccal cavity.

In the three species, some steps can be skipped during a spawning bout (e.g. steps 6 and 7 are skipped during the first bout while steps 3 to 5 are skipped during the second bout). It means that some spawning bouts lack egg laying or pelvic fin presentation (presumably when sperm is released).

The females laid between 7 and 28 eggs. Every female left the nest at least once (Table 3) between the release of the first and last egg and the mean time interval between the laying of two consecutive eggs varied from seconds to minutes (Table 4). For the three $O$. nasuta reproductions recorded in the tank that contained more than one male (i.e. two dominant males and a subordinate male, ON 3), each female

Table 4

Prevailing behaviours listed for the Ophthalmotilapia mating females.

\begin{tabular}{|c|c|c|c|c|c|}
\hline & OV $1(\mathrm{~N}=4)$ Mean $\pm \mathrm{SD}$ & ON $1(\mathrm{~N}=3)$ Mean $\pm \mathrm{SD}$ & ON $3(\mathrm{~N}=3)$ Mean $\pm \mathrm{SD}$ & OB $1(\mathrm{~N}=1)$ & ONOV $(\mathrm{N}=1)$ \\
\hline Bite (n) & $0.5 \pm 0.6$ & $0 \pm 0$ & $0.3 \pm 0.6$ & 0 & 0 \\
\hline Chase (n) & $2.5 \pm 3.1$ & $3.7 \pm 6.4$ & $17 \pm 5.6$ & 0 & 1 \\
\hline Clean (n) & $13 \pm 10.9$ & $8 \pm 11.4$ & $21.3 \pm 22$ & 3 & 2 \\
\hline Eggs interval (s) & $81.5 \pm 73.7$ & $53 \pm 26.1$ & $116 \pm 108.2$ & 20 & 389 \\
\hline Follow (n) & $14.5 \pm 2.9$ & $3.7 \pm 3.1$ & $26.7 \pm 11.7$ & 15 & 10 \\
\hline Front. Disp. (n) & $0.3 \pm 0.5$ & $0 \pm 0$ & $0 \pm 0$ & 1 & 0 \\
\hline Inside $(n)$ & $34.5 \pm 10.1$ & $13.3 \pm 5.7$ & $49.3 \pm 26.3$ & 19 & 99 \\
\hline Inside (\%) & $41.5 \pm 19.4$ & $38.9 \pm 25.3$ & $37.8 \pm 29.2$ & 34.6 & 41.1 \\
\hline Lay (n) & $22.5 \pm 3.3$ & $21.3 \pm 5.9$ & $13.3 \pm 0.6$ & 17 & 7 \\
\hline Lat disp. (n) & $7 \pm 5.9$ & $0.3 \pm 0.6$ & $4 \pm 5.2$ & 1 & 0 \\
\hline Take egg (n) & $21.3 \pm 4$ & $21.7 \pm 6.4$ & $12.3 \pm 1.2$ & 14 & 7 \\
\hline Take dummies (n) & $8 \pm 2.9$ & $2.3 \pm 0.6$ & $12 \pm 12.5$ & 7 & 11 \\
\hline
\end{tabular}

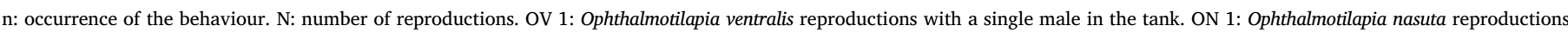

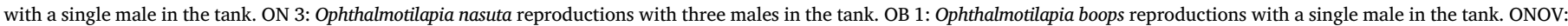

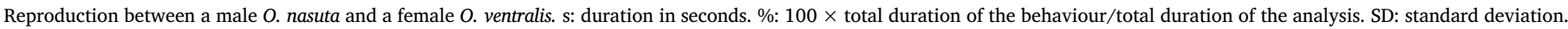




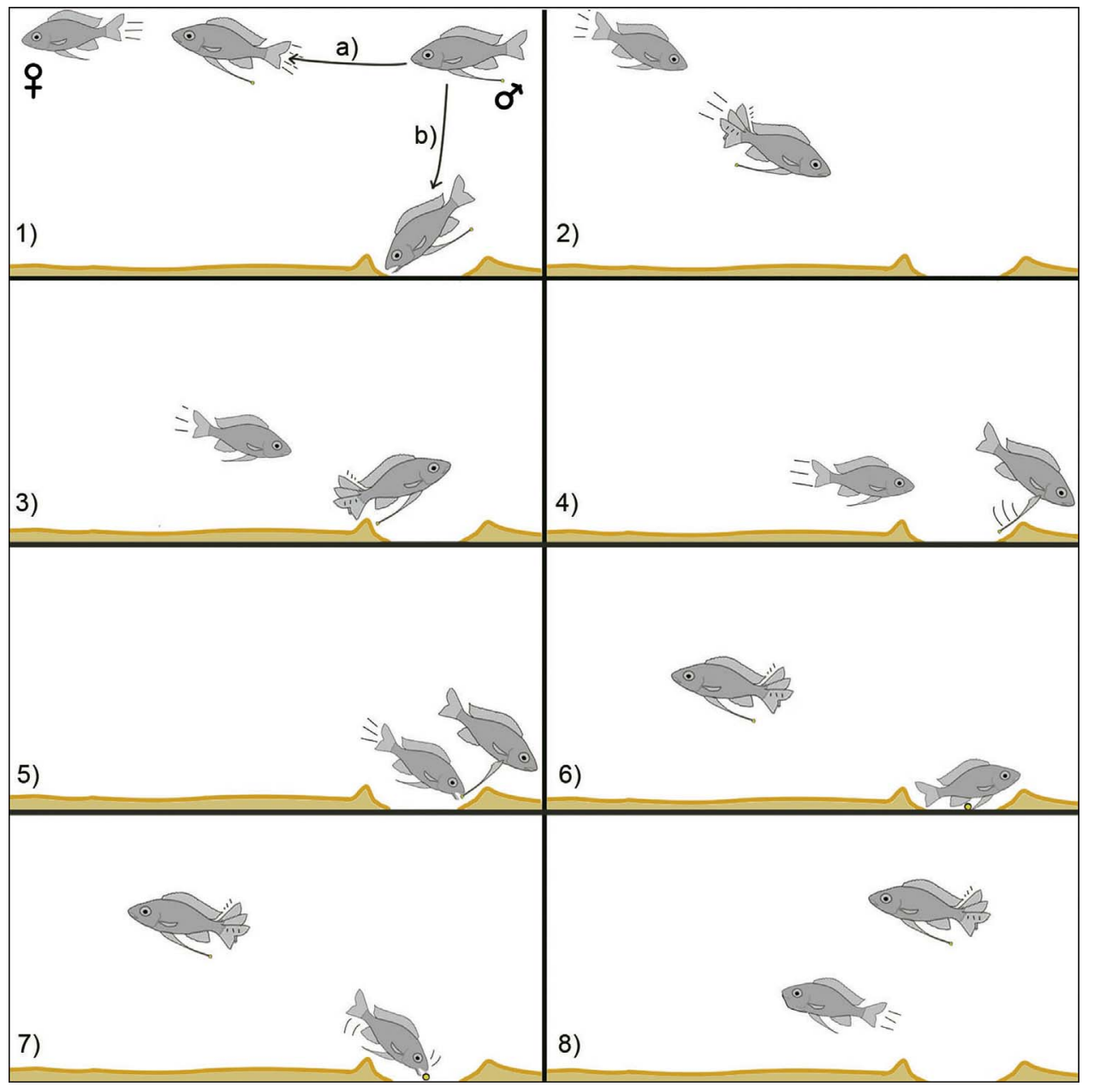

Fig. 2. The typical spawning bout of Ophthalmotilapia ventralis, $O$. nasuta, and $O$. boops. (1) The male chases the female and prepares the bower. (2) The female follows the male to his bower. (3) The male shows the bower to the female. (4) The male presents its pelvic fins. (5) The female enters the bower, swims towards the egg dummies, and opens the mouth. (6) The female lays an egg in the bower. (7) The female takes the egg in mouth. (8) The female leaves the bower. Stages 6 and 7 are generally repeated before 8 . In stages 2,3 and $6-8$, the territorial male is generally tail wagging.

laid all her eggs in the bower of only one dominant male. We did, however, record reproductions for the two dominant males. In two instances the females visited the bowers of both dominant males before they laid their eggs.

Tail wagging was indisputably the most common courtship behaviour performed by the male and we observed it before, during, and after the female visited the bower. Mating males wagged their tails $14.1 \%$ to $81.8 \%$ of the analysed period. Females also sometimes wagged their tails, but this was rare $(21.1 \pm 27.2$ times per reproductive event or $0.9 \pm 1.5 \%$ of the analysis duration). Female tail wagging and pelvic fin flickering $(18.8 \pm 19.7$ times per reproductive event or $1.2 \pm 1.3 \%$ of the analysis duration) were mainly observed just before an egg was released. The mating male often stopped tail wagging to chase another interacting fish or to present its 'egg dummies' to the female. In $60.4 \%$ of the cases, the pelvic fin presentation was followed by the female swimming with her mouth open towards the 'egg dummies'. Although it was not possible to see sperm emission on film or during direct observations, it most likely happened at this point. With a mean of $115.2 \pm 87$ chases (also towards males for ON 3 reproductions), the mating male invested a lot of energy in territory defence during the courtship and mating process. However, agonistic interactions other than chases (i.e. bites, lateral displays, and frontal displays) were not frequent during courtship and mating (Tables 3 and 4).

\subsection{Inter- and intraspecific differences}

Using the screen plot and the Kaiser-Guttman rule, the first four PCs

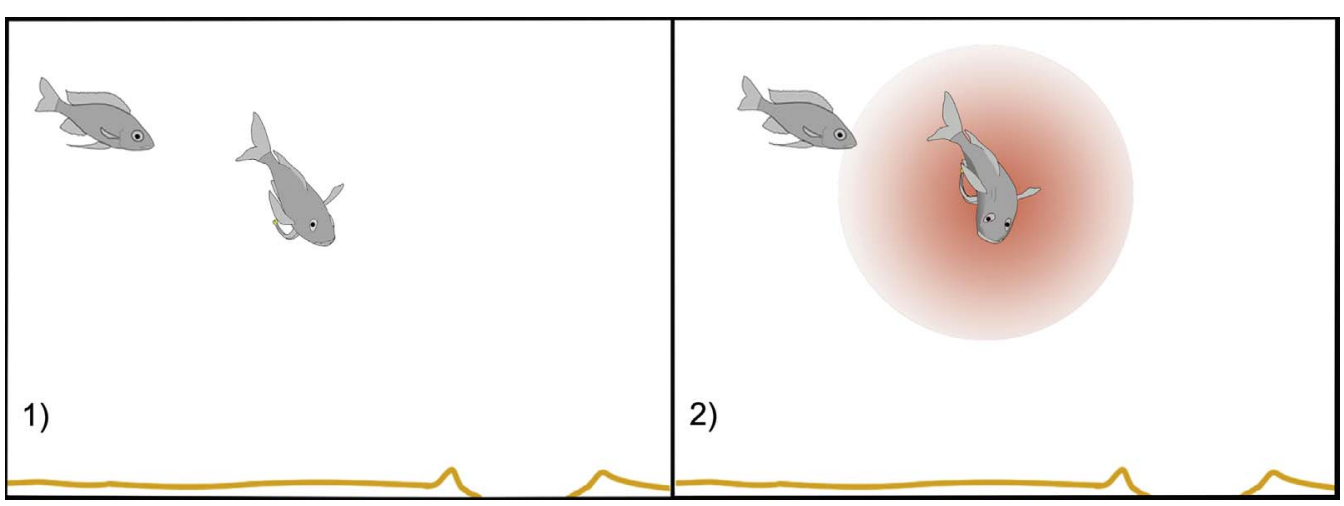

Fig. 3. Schematic representation of the courtship behaviour call 'invite' in Ophthalmotilapia ventralis and $O$. boops. (A) The male positions himself in front of the female (often head down). (B) He performs a fast-lateral movement of anterior part of his body. This movement results in the emission of an acoustic signal, the intensity of which drops on short distance (red sphere). This behaviour was always performed very close to the female. 


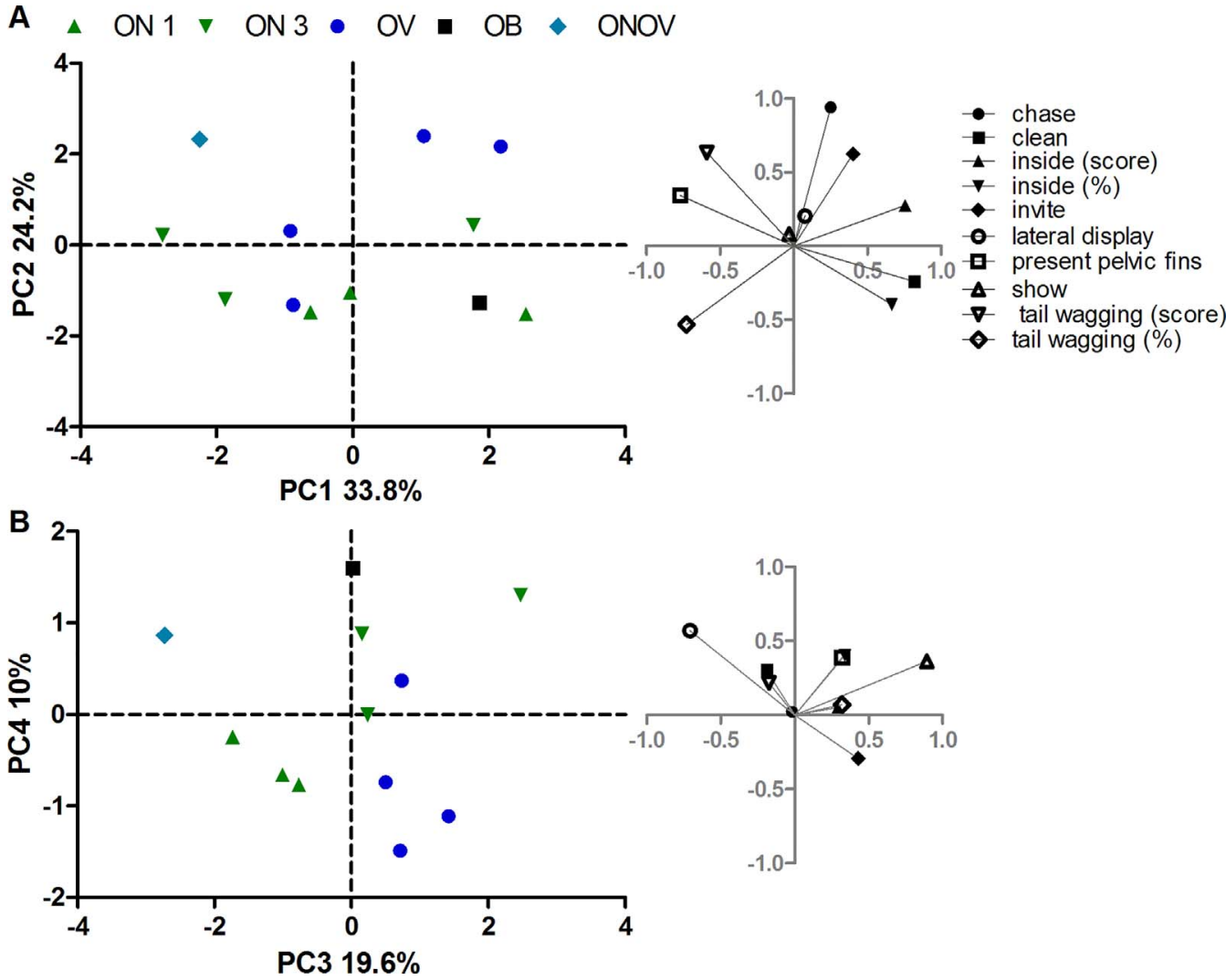

A $\triangle \mathrm{ON} 1 \boldsymbol{\mathrm { V }} 3 \cdot \mathrm{ON}$ - OB $\bullet \mathrm{ONOV}$
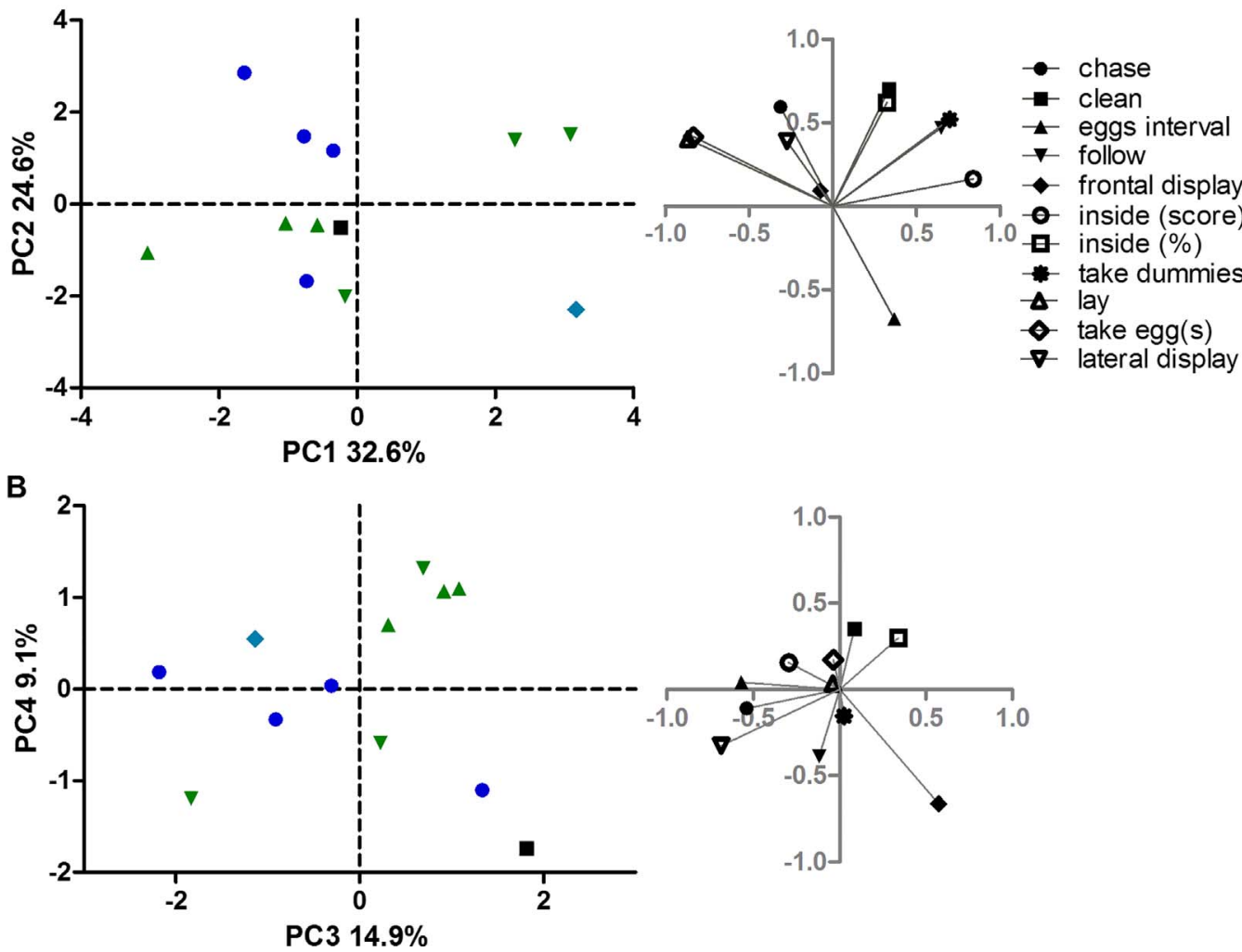

Fig. 4. Principal component analysis based on the behaviours recorded for Ophthalmotilapia mating males. (A) Coordinates of the individuals (left) and loadings of the variables (right) on PC1 vs. PC2. (B) Coordinates of the individuals (left) and loadings of the variables (right) on PC3 vs. PC4. OV: the male $O$. ventralis mated with a female $O$. ventralis. ON1: the male $O$. nasuta mated with a female $O$. nasuta and there was no other male in the tank. ON3: the male $O$. nasuta mated with a female $O$. nasuta and there were two other males in the tank. OB: the male $O$. boops mated with a female $O$. boops. ONOV: the male $O$. nasuta mated with a female $O$. ventralis. Score: number of events recorded. \%: (total behaviour duration/total analysis duration) $\mathrm{x}$ 100.

Fig. 5. Principal component analysis based on the behaviours recorded for Ophthalmotilapia mating females. (A) Coordinates of the individuals (left) and loadings of the variables (right) on PC1 vs. PC2. (B) Coordinates of the individuals (left) and loadings of the variables (right) on PC3 vs. PC4. OV: the male $O$. ventralis mated with a female $O$. ventralis. ON1: the male $O$. nasuta mated with a female $O$. nasuta and there was no other male in the tank. ON3: the male $O$. nasuta mated with a female $O$. nasuta and there were two other males in the tank. OB: the male $O$. boops mated with a female $O$. boops. ONOV: the male $O$. nasuta mated with a female $O$. ventralis. Egg interval: mean duration between the laying of two successive eggs. Score: number of events recorded. \%: (total behaviour duration/total analysis duration) x 100 . 
of the principal component analysis were investigated. Regarding this analysis, male and female behaviours show much overlap among species (Figs. 4 and 5). However, there was less overlap on the PC3 vs PC4 graph of the male PCA; ON 1 and OV 1 males form two distinct groups on the third axis (Fig. 4C), and ON 1 and ON 3 males form two separate groups along PC3 and PC4 (Fig. 4C), these axes being related to the high loadings of the number of 'show' and 'lateral display' (Fig. 4D). In both analyses (male and female behaviour), the heterospecific interaction clearly separated from the conspecific ones on a combination of the first and second axis and, for males, also on the third axis (Figs. 4 and 5).

We saw no 'invite' behaviour in any of the seven reproduction events involving males of $\boldsymbol{O}$. nasuta (Table 3), which also explains part of their position in the male PCAs (Fig. 4). This behaviour was recorded 20 times during the $\mathrm{OB}$ reproduction and 161 times during the $\mathrm{OV}$ reproductions ( $0,40,56$, and 65 times). Although it was not performed during the heterospecific (ONOV) reproduction, the female $O$. ventralis did enter the bower and laid eggs with the $O$. nasuta male. This was, however, the reproduction with the lowest number of eggs laid (7 eggs) and the longest inter-egg intervals (Table 4). During the OV 1, OB 1, and ON 1 reproductions much more eggs were laid $(22.5 \pm 3.3,17$, and $21.3 \pm 5.9$ eggs per reproduction, respectively). The number of eggs laid during ON 3 reproductions was also low (13.3 \pm 0.6 eggs per reproduction).

The statistical comparisons of behaviour focused on the four OV reproductions and the three ON 1 reproductions recorded with a single male in the tank. We could not include OB and ONOV reproductions to these analyses because we recorded only one reproduction for these setups. Except for the 'invite' behaviour (absent in $O$. nasuta), the courting and mating behaviours displayed by $O$. ventralis and $O$. nasuta males are quantitatively $\left(\mathrm{T}^{2}\right.$ Hotelling $=4227.7, \quad \mathrm{~F} 5,1=169.1$, $P=0.06)$ and qualitatively similar. For the males, we only found a significant difference for the number of 'show' events. This was higher in $O$. ventralis $(\mathrm{t}=15.2, \mathrm{dl}=5, P=0.00002)$. Similarly, we found only one difference in the behaviour of the females: females of $O$. ventralis followed males $(\mathrm{t}=4.8, \mathrm{dl}=5, P=0.0049)$ more often than females of $O$. nasuta.

\subsection{Sound production}

Among the recorded behaviours, sounds with a potential communicative value were only recorded during the 'invite' behaviour (Fig. 3), which implies that we recorded no sound for O. nasuta (ON $1, \mathrm{ON} 3$, and ONOV). This acoustic signal was recorded only when the invite behaviour was intense (i.e. when the spasm movement was very quick) and performed very close to the hydrophone. We analysed 51 pulses recorded from three different $O$. ventralis males. These broadband frequency pulses (Fig. 6) had most energy between 100 and $750 \mathrm{~Hz}$ (mean $\pm \mathrm{SD}, 310 \pm 176 \mathrm{~Hz}$ ) and had relatively short pulse duration $(8.8 \pm 4.1 \mathrm{~ms})$. They were emitted singly or in pairs, except for one sound that looked like a pulse train. In this case, nine pulses were emitted at a pulse period of $157 \pm 32 \mathrm{~ms}$.

\section{Discussion}

Despite the variation in the number of steps between the spawning bouts of a reproduction event, the reproductive behaviours of the three Ophthalmotilapia species (O. ventralis, O. nasuta, and $O$. boops) were similar. The only qualitative difference was the absence of the 'invite' behaviour and the associated sound in $O$. nasuta. As in $O$. ventralis, male $O$. boops may produce sounds because they also display strong spasms during the 'invite' behaviours and as those spasms were associated with sound production in the former species (see Section 4.1 for more details). However, this needs to be confirmed as no hydrophone was recording during the $\mathrm{OB}$ reproduction. The comparison of $O$. nasuta and $O$. ventralis reproductive behaviour also revealed some quantitative differences: male $O$. ventralis performed significantly more 'shows' and
A.

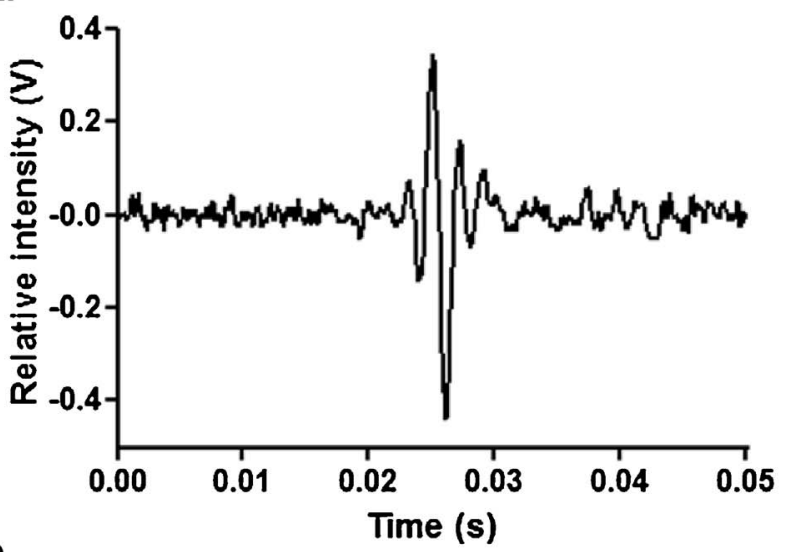

B.

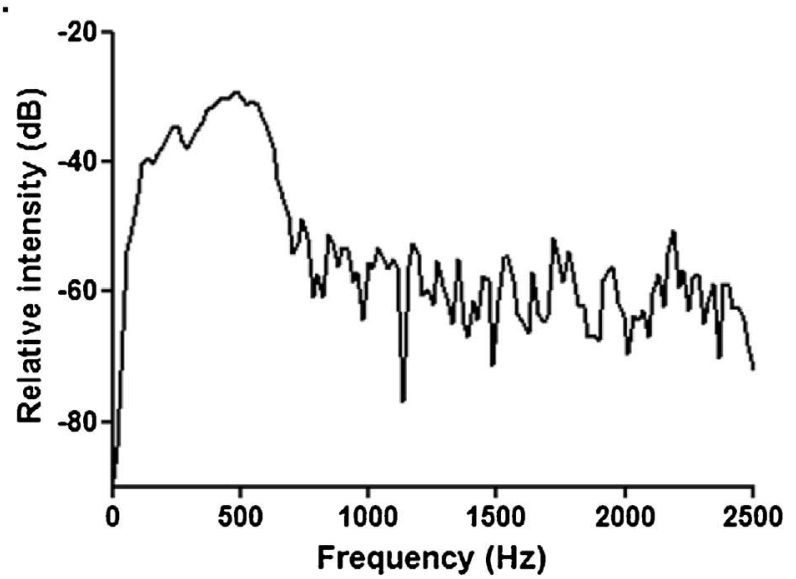

C.
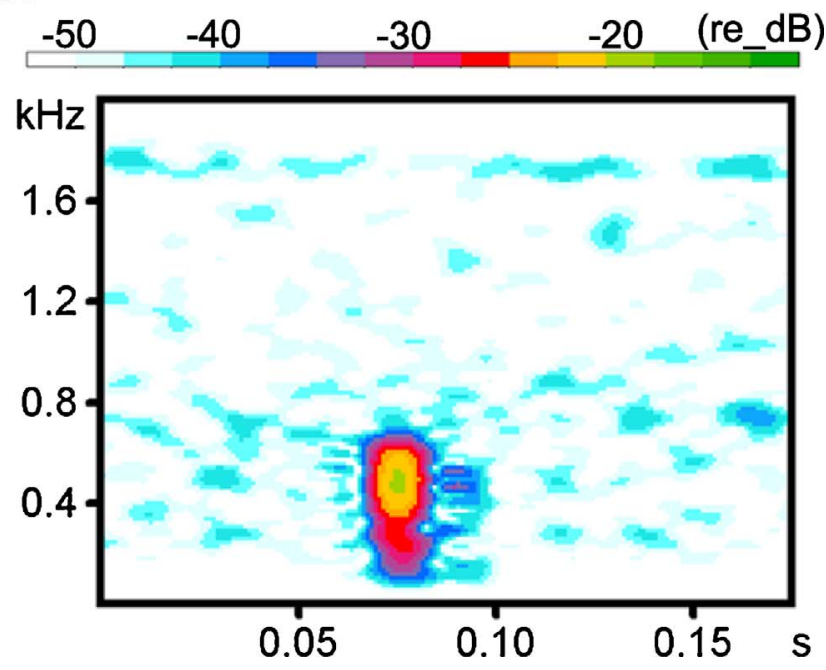

Fig. 6. Acoustic signal associated with the 'invite' behaviour of a male Ophthalmotilapia ventralis. (A) Waveform, (B) logarithmic power spectrum, and (C) spectrogram (FFT length: 256 points, frame size: $75 \%$, flat top window, overlap: $98.4 \%$ ) of an 'invite' pulse.

O. ventralis females followed the male significantly more often. Interestingly, Konings (2014) suggested that the large crater bowers of $O$. nasuta stand out from the surrounding rocks and must be obvious to the females. Male $O$. ventralis and $O$. boops may perform the 'invite' behaviour and show their bower more often to the female because the latter is less conspicuous and potentially less appealing to the female.

The maternal mouthbrooding that resulted from the heterospecific reproduction only lasted for two days, the female laid very few eggs (only 7), and the inter-egg interval was longer. This suggests that when 
mating with a heterospecific male, the motivation of the $O$. ventralis female to produce a large clutch size may be lower than when mating with a conspecific male. Selz et al. (2014) reported similar trends for two Lake Victoria cichlids tested using a 2-way mate choice design. It has also been shown that female songbirds stimulated by conspecific songs lay more eggs than females triggered by heterospecific songs (Bentley et al., 2000). In other words, differences in male courtship signal can explain lower female inclination to lay eggs.

\subsection{Terminological considerations related to 'quiver', 'invite' and 'tail wagging'}

Although the 'quiver' display has been reported for many cichlid species (e.g. Baerends and Baerends-Van Roon, 1950b; Rowland, 1978; Lobel, 1998; Rice and Lobel, 2003; Amorim et al., 2004, 2008; Simoes et al., 2008; Bertucci et al., 2010; Verzijden et al., 2010; Maruska et al., 2012), we did not observe this behaviour during any of the twelve reproductions of the Ophthalmotilapia species. This is surprising, since Haesler et al. (2009), and Immler and Taborsky (2009) mentioned that $O$. ventralis males 'quivered' at the entrance of the nest. It is possible that Ophthalmotilapia does not display the 'quiver' behaviour in tanks, but this seems unlikely because this behaviour was often recorded in artificial conditions for other cichlid species (e.g. Amorim et al., 2008; Bertucci et al., 2010; Maruska et al., 2012). It seems more plausible that the terminology was used in a different meaning by Haesler et al. (2009) and Immler and Taborsky (2009) to describe the intense tail wagging observed when the male shows the location of the bower to the female. During quivering, the fish is generally positioned head down and with its head bent sideways over a small angle (Baerends and Baerends-Van Roon, 1950b). Often, this movement is repeated a few times and then carried out alternately to the left and to the right. The centre of the movement lies just behind the operculae and, if it is intense, it propagates backwards along the body and the tail is swept appreciably sideways. In contrast, during tail wagging, the action consists of vigorous lateral body undulations with the propulsive force counterbalanced by beating the pectoral fins forwards. Finally, the 'invite' behaviour that males use to guide a gravid female to their bower was recorded in $O$. ventralis and $O$. boops and consists of flexing the body and performing a spasm like those observed during quivering. However, whereas a 'quiver' is composed of successive spasms, the 'invite' is composed of a single spasm (or several isolated ones) (Baerends and Baerends-Van Roon, 1950b).

\subsection{Sound associated with reproductive behaviour in Ophthalmotilapia}

Multiple pulsed sounds have been recorded for many haplochromines from lakes Malawi and Victoria (listed in Longrie et al., 2013) and for some Tropheini (Nelissen, 1978), an endemic LT tribe nested within the Haplochromini (Day et al., 2008). Among the endemic species of the Great African Lakes, O. ventralis and O. nasuta (Ectodini), and Neolamprologus pulcher (Lamprologini) are the only non-haplochromine species in which sound production has been investigated. In $N$. pulcher, which is a highly social cichlid, no communicative sound has been recorded (Pisanski et al. 2014). In Ophthalmotilapia, sounds were only recorded when intense 'invite' events were performed near the hydrophone. Since these single-pulsed sounds were very weak, their communicative value is questionable. It would be interesting to collect data from the many other LT tribes to trace the evolutionary history of sound production in cichlids from the Great African lakes.

During the 'invite' behaviour of $O$. ventralis, every single pulse sound was associated with a spasm movement. The hydrodynamic component resulting from the spasm movement may be important: this behaviour was always performed close to the receiver. The role of the lateral line in non-contact aggressive interactions has been demonstrated in the cichlid Astatotilapia burtoni (Butler and Maruska, 2015). Like the 'invite' behaviour in Ophthalmotilapia, opponents are very close $(<1$ body length) to the signal emitter in A. burtoni. In the Nile tilapia, Oreochromis niloticus (Cichlidae), fast and bilateral contractions of the anterior hypaxial musculature were shown to be responsible for sound emission (Longrie et al., 2009). A similar mechanism was reported in a more distantly related species, the pyramid butterflyfish (Chaetodontidae), Hemitaurichthys polylepis (Boyle and Tricas, 2010). The fastlateral movements of the head observed for $O$. ventralis (also visible in the high-speed movies in the supplementary online Appendix) suggest that their sounds result from a fast and unilateral contraction of the anterior part of the trunk musculature. The pattern observed in Ophthalmotilapia sound production is like the one observed during the production of submissive sounds in the clownfish (Pomacentridae), Amphiprion frenatus (Dr. O. Colleye, personal communication). The latter sounds were always emitted in a submissive posture while exhibiting head shaking movements (Colleye and Parmentier, 2012). A common factor in the submissive sounds of clownfish and the inviting sounds of Ophthalmotilapia is that they are associated with behaviours that convey a message of non-aggression. Since they necessitate no specific features, sound production mechanisms involving fast contractions of the hypaxial musculature may have evolved independently in several Perciformes.

\subsection{Egg deposition and sperm release in Ophthalmotilapia}

Reproduction time in $O$. ventralis and $O$. nasuta, measured as the time between the deposition of the first and the last egg, lasted approximately half an hour $(28.2 \pm 22.9 \mathrm{~min}$ for $O$. ventralis and $23.1 \pm 15.8 \mathrm{~min}$ for $O$. nasuta). This is comparable to the $35 \mathrm{~min}$ on average observed for $O$. ventralis reproduction in the wild (Immler and Taborsky, 2009). In each of the three species, the mating female left the bower of the male several times during spawning. In the field, female $O$. ventralis generally visit and collect the sperm from several males (Haesler, 2007; Immler and Taborsky, 2009; Haesler et al., 2011). For the three $O$. nasuta reproductions recorded in a multiple males' setup, all eggs from a single clutch were laid in a single bower, but the three females visited the territory of the two dominant males during reproduction and two of them even entered both bowers.

Although every male recorded in this study built a bower, our data corroborate that $O$. nasuta is a crater-building species (i.e. species that build a sand mount with a crater at its top) and $O$. ventralis a non-crater building species (Konings, 2014). Even though all the reproductions analysed in this study took place in bowers, it is not an indispensable condition for a female $O$. ventralis to mate since we observed a mouthbrooding female in a reserve tank devoid of any substratum. Crater-builders are believed to release sperm in the crater before the female enters the bower while non-crater building species (e.g. those that manage a sandy or rocky patch) with egg dummies or egg spots release sperm directly into the mouth of females (Morita et al., 2014). The same authors argued that a crater shape prevented sperm from being washed away and they found increased sperm longevity in craterbuilding species. Our results do not support the difference of sperm uptake in crater and non-crater species proposed by Morita et al. (2014). In all but one of the reproductions, the females indubitably swam towards male egg dummies with an opened mouth (O. ventralis: $8 \pm 4.4$ times; O. nasuta: $7.2 \pm 9.5$ times; $O$. boops: 7 times; $O$. ventralis female/O. nasuta male: 11 times). In addition, every male stopped at the entrance of the bower, tail wagging vigorously just before the female entered the nest. This behaviour was generally followed by a pelvic fin presentation inside the bower. Furthermore, Haesler (2007) found that the sperm of $O$. ventralis was viable for at least $900 \mathrm{~s}$ which is longer than all the sperm longevities reported by Morita et al. (ca. $550 \mathrm{~s}$ on average for $O$. nasuta and ca. $400 \mathrm{~s}$ on average for $O$. ventralis). Because $O$. ventralis females collect the sperm of several males but do not lay eggs in each bower (Haesler et al., 2011), the time a female spends collecting sperm from different males could be measured to test an alternative hypothesis explaining the interspecific differences in sperm 
longevity of LT cichlids. Sexual selection acting during sperm shopping by the female was already suggested to be responsible for the sequential polyandry in O. ventralis (Immler and Taborsky, 2009).

\subsection{Hybridisation between sympatric species of Ophthalmotilapia}

The repeated introgression of mitochondrial DNA from Ophthalmotilapia species into O. nasuta (Nevado et al., 2011) suggests that male $O$. nasuta are (or were) able to mate with congeners. Here, we recorded a heterospecific mating between a male $O$. nasuta and a female $O$. ventralis, which also suggests there are no hermetic prezygotic barriers between males of $O$. nasuta and females of $O$. ventralis, at least when there is no conspecific partner available. However, this female laid only very few eggs and the time interval between the deposition of two successive eggs was very long. Moreover, although she repeatedly swam with an open mouth towards the egg dummies of the male, the mouthbrooding was aborted after a couple of days. This could be a choice made by the female because there were relatively few eggs but it may also have resulted from postmating incompatibilities (e.g. no fertilization, no hatching, or lower survival rate). However, after this study, and in a different setting, we did obtain viable offspring from reproductive events between male $O$. nasuta and female $O$. ventralis. It should be noted that, also here, no conspecific males were present and that only four hybrid specimens survived. Using internally calibrated clocks, Stelkens et al. (2009) estimated that a complete inviability of haplochromine hybrids was reached 4.4 my after a speciation event (8.5 and 18.4 my with relaxed clocks calibrated using cichlid fossil records and the fragmentation of Gondwanaland, respectively) while Koblmuiller et al. (2004) considered that species within the Ophthalmotilapia clade evolved during a diversification event that may have occurred between 2.5 and 3 MYA. As they used different calibration points, comparisons between these two studies should be considered with caution. However, theses estimations suggest that a complete inviability of Ophthalmotilapia hybrids is unlikely though postmating incompatibilities could be relatively high. Since we could not identify hermetic behavioural barriers to the hybridisation of Ophthalmotilapia species living in sympatry, further investigations are needed to pinpoint the role of other pre- and/or postzygotic isolations.

\section{Acknowledgements}

We are grateful to Siegfried Loose for his advice on the rearing of Ophthalmotilapia. This study is part of the GENBAS project which is funded by the Belspo BRAIN-be program.

\section{Appendix A. Supplementary data}

Supplementary data associated with this article can be found, in the online version, at https://doi.org/10.1016/j.zool.2017.12.001.

\section{References}

Akamatsu, T., Okumura, T., Novarini, N., Yan, H.Y., 2002. Empirical refinements applicable to the recording of fish sounds in small tanks. J. Acoust. Soc. Am. 112, 3073-3082

Amorim, M.C.P., Knight, M.E., Stratoudakis, Y., Turner, G.F., 2004. Differences in sounds made by courting males of three closely related Lake Malawi cichlid species. J. Fish Biol. 65, 1358-1371.

Amorim, M.C.P., Simões, J.M., Fonseca, P.J., Turner, G.F., 2008. Species differences in courtship acoustic signals among five Lake Malawi cichlid species (Pseudotropheus spp.). J. Fish Biol. 72, 1355-1368.

Baerends, G.P., Baerends-Van Roon, J.M., 1950a. Description of the elementary actions. In: Baerends, G.P., Baerends-Van Roon, J.M. (Eds.), An Introduction to the Study of the Ethology of Cichlid Fishes. Brill, Leiden pp. 21-40.

Baerends, G.P., Baerends-Van Roon, J.M., 1950b. An Introduction to the Study of the Ethology of Cichlid Fishes. Behaviour. Brill Leiden.

Baylis, J.R., 1976. Quantitative study of long-term courtship: II: A comparative study of the dynamics of courtship in two New World cichlid fishes. Behaviour 59, 117-161.

Bentley, G.E., Wingfield, J.C., Morton, M.L., Ball, G.F., 2000. Stimulatory effects on the reproductive axis in female songbirds by conspecific and heterospecific male song.
Horm. Behav. 37, 179-189.

Bertucci, F., Beauchaud, M., Attia, J., Mathevon, N., 2010. Sounds modulate males' aggressiveness in a cichlid fish. Ethology 116, 1179-1188.

Boyle, K.S., Tricas, T.C., 2010. Pulse sound generation, anterior swim bladder buckling and associated muscle activity in the pyramid butterflyfish, Hemitaurichthys polylepis. J. Exp. Biol. 213, 3881-3893.

Brichard, P., 1989. Pierre Brichard's Book of Cichlids and All the Other Fishes of Lake Tanganyika. TFH, New Jersey.

Butler, J.M., Maruska, K.P., 2015. The mechanosensory lateral line is used to assess opponents and mediate aggressive behaviors during territorial interactions in an African cichlid fish. J. Exp. Biol. 218, 3284-3294.

Colleye, O., Parmentier, E., 2012. Overview on the diversity of sounds produced by clownfishes (Pomacentridae): importance of acoustic signals in their peculiar way of life. PLoS One 7, e49179.

Day, J.J., Cotton, J.A., Barraclough, G., Barraclough, T.G., 2008. Tempo and mode of diversification of Lake Tanganyika cichlid fishes. PLoS One 3, e1730.

Egger, B., Koblmüller, S., Sturmbauer, C., Sefc, K.M., 2007. Nuclear and mitochondria data reveal different evolutionary processes in the Lake Tanganyika cichlid genus Tropheus. BMC Evol. Biol. 14, 1-14.

Egger, B., Mattersdorfer, K., Sefc, K.M., 2010. Variable discrimination and asymmetric preferences in laboratory tests of reproductive isolation between cichlid colour morphs. J. Evol. Biol. 23, 433-439.

Friard, O., Gamba, M., 2016. BORIS: a free, versatile open-source event-logging software for video/audio coding and live observations. Methods Ecol. Evol. 7, 1325-1330.

Haesler, 2007. Sequential Mate Choice Decisions and Sperm Competition in Mouthbrooding Cichlids. Ph.D. Thesis. University of Bern, Switzerland.

Haesler, M.P., Lindeyer, C.M., Taborsky, M., 2009. Reproductive parasitism: male and female responses to conspecific and heterospecific intrusions at spawning in a mouthbrooding cichlid Ophthalmotilapia ventralis. J. Fish Biol. 75, 1845-1856.

Haesler, M.P., Lindeyer, C.M., Otti, O., Bonfils, D., Heg, D., Taborsky, M., 2011. Female mouthbrooders in control of pre- and postmating sexual selection. Behav. Ecol. 22, 1033-1041.

Hanssens, M., Snoeks, J., Verheyen, E., 1999. A morphometric revision of the genus Ophthalmotilapia (Teleostei, Cichlidae) from Lake Tanganyika (East Africa). Zool. J. Linn. Soc. 125, 487-512.

Immler, S., Taborsky, M., 2009. Sequential polyandry affords post-mating sexual selection in the mouths of cichlid females. Behav. Ecol. Sociobiol. 63, 1219-1230.

Keller, I., Wagner, C.E., Greuter, L., Mwaiko, S., Selz, O.M., Sivasundar, A., Wittwer, S., See, 2013. Population genomic signatures of divergent adaptation, gene flow and hybrid speciation in the rapid radiation of Lake Victoria cichlid fishes. Mol. Ecol. 22, $2848-2863$.

Koblmüller, S., Salzburger, W., Sturmbauer, C., 2004. Evolutionary relationships in the sand-dwelling cichlid lineage of Lake Tanganyika suggest multiple colonization of rocky habitats and convergent origin of biparental mouthbrooding. J. Mol. Evol. 58, 79-96.

Koblmüller, S., Duftner, N., Sefc, K.M., Aibara, M., Stipacek, M., Blanc, M., Egger, B., Sturmbauer, C., 2007. Reticulate phylogeny of gastropod-shell-breeding cichlids from Lake Tanganyika - the result of repeated introgressive hybridization. BMC Evol. Biol. 7, 7.

Koblmüller, S., Sefc, K.M., Sturmbauer, C., 2008. The Lake Tanganyika cichlid species assemblage: recent advances in molecular phylogenetics. Hydrobiologia 615, 5-20.

Kocher, T.D., 2004. Adaptive evolution and explosive speciation: the cichlid fish model. Nat. Rev. 5, 288-298.

Konings, A., 2014. Featherfins in their Natural Habitat. Cichlid Press.

Kornfield, I., Smith, P.F., 2000. African cichlid fishes: model systems for evolutionary biology. Annu. Rev. Ecol. Syst. 31, 163-196.

Kuwamura, T., 1986. Parental care and mating systems of cichlid fishes in Lake Tanganyika: a preliminary field survey. J. Ethol. 4, 129-146.

Liem, K.F., 1981. A phyletic study of the Lake Tanganyika cichlid genera Asprotilapia, Ectodus, Lestradea, Cunningtonia, Ophthalmochromis, and Ophthalmotilapia. Bull. Mus. Comp. Zool. Harvard 149, 191-214.

Lobel, P.S., 1998. Possible species specific courtship sounds by two sympatric cichlid fishes in Lake Malawi. Environ. Biol. Fishes 52, 443-452.

Longrie, N., Wassenbergh, V.S., Vandewalle, P., Mauguit, Q., Parmentier, E., 2009. Potential mechanism of sound production in Oreochromis niloticus (Cichlidae). J. Exp. Biol. 202, 3395-3402.

Longrie, N., Poncin, P., Denoël, M., Gennotte, V., Delcourt, J., Parmentier, E., 2013 Behaviours associated with acoustic communication in Nile tilapia (Oreochromis niloticus). PLoS One 8, e61467.

Loose, S., 2007. Fadenmaulbrüter im Tanganjikasee. Dähne Verlag, Ettlingen.

Maruska, K.P., Ung, U.S., Fernald, R.D., 2012. The African cichlid fish Astatotilapia burtoni uses acoustic communication for reproduction: sound production, hearing, and behavioral significance. PLoS One 7, e37612.

McElroy, D.M., Kornfield, I., 1990. Sexual selection, reproductive behavior, and speciation in the mbuna species flock of Lake Malawi (Pisces: Cichlidae). Environmental Biol. Fishes 28, 273-284.

Morita, M., Awata, S., Yorifuji, M., Ota, K., Kohda, M., Ochi, H., 2014. Bower-building behaviour is associated with increased sperm longevity in Tanganyikan cichlids. J. Evol. Biol. 27, 2629-2643.

Nelissen, M.H.J., 1978. Sound production by some Tanganyikan cichlid fishes and a hypothesis for the evolution of their communication mechanisms. Behaviour 64, 137-147.

Nevado, B., Fazalova, V., Backeljau, T., Hanssens, M., Verheyen, E., 2011. Repeated unidirectional introgression of nuclear and mitochondrial DNA between four congeneric Tanganyikan cichlids. Mol. Biol. Evol. 28, 2253-2267.

Pisanski, K., Marsh-Rollo, S.E., Balshine, S., 2014. Courting and fighting quietly: a lack of 
acoustic signals in a cooperative Tanganyikan cichlid fish. Hydrobiologia 748, 87-97. Rice, A.N., Lobel, P.S., 2003. The pharyngeal jaw apparatus of the Cichlidae and Pomacentridae: function in feeding and sound production. Rev. Fish Biol. Fish. 13, 433-444.

Rice, W.R., 1989. Analyzing tables of statistical tests. Evolution 43, 223-225.

Rowland, W.J., 1978. Sound production and associated behavior in the jewel fish, Hemichromis bimaculatus. Behaviour 64, 125-136.

Rüber, L., Meyer, A., Sturmbauer, C., Verheyen, E., 2001. Population structure in two sympatric species of the Lake Tanganyika cichlid tribe Eretmodini: evidence for introgression. Mol. Ecol. 10, 1207-1225.

Salzburger, W., Meyer, A., Baric, S., Verheyen, E., Sturmbauer, C., 2002a. Phylogeny of the Lake Tanganyika cichlid species flock and its relationship to the Central and East African haplochromine cichlid fish faunas. Syst. Biol. 51, 113-135.

Salzburger, W., Baric, S., Sturmbauer, C., 2002b. Speciation via introgressive hybridization in East African cichlids? Mol. Ecol. 11, 619-625.

Schupke, P., 1994. Die Pflege von Ophthalmotilapia. Die Aquarienzeitschrift 6, 350-354. Seehausen, O., 2004. Hybridization and adaptive radiation. Trends Ecol. Evol. 19, 198-207.

Seehausen, O., Terai, Y., Magalhaes, I.S., Carleton, K.L., Mrosso, H.D.J., Miyagi, R., Van Der Sluijs, I., Schneider, M.V., Maan, M.E., Tachida, H., Imai, H., Okada, N., 2008. Speciation through sensory drive in cichlid fish. Nature 455, 620-627.
Sefc, K.M., 2011. Mating and parental care in Lake Tanganyika cichlids. Int. J. Evol. Biol. 2011, 470875.

Sefc, K.M., Mattersdorfer, K., Ziegelbecker, A., Neuhüttler, N., Steiner, O., Goessler, W., Koblmüller, S., 2017. Shifting barriers and phenotypic diversification by hybridisation. Ecol. Lett. 20, 651-662.

Selz, O.M., Pierotti, M.E.R., Maan, M.E., Schmid, C., Seehausen, O., 2014. Female preference for male color is necessary and sufficient for assortative mating in 2 cichlid sister species. Behav. Ecol. 25, 612-626.

Simoes, J.M., Duarte, G.D., Fonseca, P.J., Turner, G.F., Amorim, C.P., 2008. Courtship and agonistic sounds by the cichlid fish Pseudotropheus zebra. J. Acoust. Soc. Am. 124 1332-1338.

Smith, P.F., Konings, A., Kornfield, I., 2003. Hybrid origin of a cichlid population in Lake Malawi: implications for genetic variation and species diversity. Mol. Ecol. 12, 2497-2504.

Stelkens, R.B., Young, K.A., Seehausen, O., 2009. The accumulation of reproductive incompatiblities in African cichlid fish. Evolution 64, 617-633.

Taborsky, M., Limberger, D., 1981. Helpers in fish. Behav. Ecol. Sociobiol. 8, 143-145.

Verzijden, M.N., Van Heusden, J., Bouton, N., Witte, F., Ten Cate, C., Slabbekoorn, H. 2010. Sounds of male Lake Victoria cichlids vary within and between species and affect female mate preferences. Behav. Ecol. 21, 548-555. 